\title{
Trends in Seroprevalence of Chikungunya Over a Period of Ten Years, in a Tertiary Care Centre in Mahabubnagar District
}

\author{
Dr. Pallati Alekhya ${ }^{1}$, Dr. J. K. Surekha ${ }^{2}$, Dr. V. Rama Devi ${ }^{3}$, Dr. Udayasri B ${ }^{4 *}$
}

${ }^{1}$ Assistant Professor, ${ }^{2}$ Associate Professor, ${ }^{3}$ Professor \& HOD, Department of Microbiology, Government Medical College Mahabubnagar, Metugadda, Mahabubnagar District, Telangana 509001, India

${ }^{4}$ Assistant Professor, Department of Microbiology, Niloufer Hospital, Red Hills, Baazar Ghat, Lakdi Ka Pul, Hyderabad - 500004 , India

DOI: $\underline{10.36348 / \mathrm{sjpm} .2019 . \mathrm{v} 04 \mathrm{i} 12.006}$

| Received: 20.12.2019| Accepted: 27.12.2019 | Published: 30.12 .2019

*Corresponding author: Dr. Udayasri B

\section{Abstract}

CHIKV is a re-emerging arboviral disease. Increase incidence is seen in many parts of India. This study was done to see the trends over a period of 10years. A total of 3676 samples were studied. Their demographic data and CHIK antibody detection was detected. This data was analyzed in 2 half's of 5 years each. Over 10 years, 368 were positive for CHIK IgM ELSIA. Majority were females. Age group affected was middle age. Over the 10 years the disease was seen in all seasons of the year. There were no deaths seen due to CHIKV infection. CHIKV infection has high morbidity but is a self limiting disease and vector control is the only prevention.

Keywords: CHIKV, IgM ELISA, arboviral, seroprevalence, Mahabubnagar, Chikungunya.

Copyright @ 2019: This is an open-access article distributed under the terms of the Creative Commons Attribution license which permits unrestricted use, distribution, and reproduction in any medium for non-commercial use (NonCommercial, or CC-BY-NC) provided the original author and sources are credited.

\section{INTRODUCTION}

Arboviruses (arthropod-borne viruses) are diverse group of RNA viruses that are transmitted by bloodsucking arthropods (insect vectors) from one vertebrate host to another. Chikungunya (CHIK) virus belongs to family Togaviridae and genus Alpha virus among the Arboviruses group. The name is derived from the Makonde word "kungunyala" meaning "that which bends up or gets folded" in reference to the stooped posture, which develops as a result of the severe joint pain that occurs during the course of illness. Chikungunya virus is a spherical enveloped virus with positive sense ssRNA [1]. Chikungunya fever is a re-emerging viral disease [2]. The virus is primarily transmitted to humans via the bite of an infected Aedes spp mosquito. CHIKV was $1^{\text {st }}$ recognized as a human pathogen during the 1950s in Africa, and since then, cases have been identified in many countries in Africa and Asia [3-5]. It is an epidemic viral disease responsible for significant global public health problem [3-9]. This study was done to know the trends in the Chikungunya virus over a period of 10 years.

\section{MATERIAL AND METHODS}

A retrospective review of the serological data of all the patients suffering from fever with or without joint pains attending at a tertiary care hospital at
Mahabubnagar district Telangana, from 2009 to 2018 was conducted. Patients who were tested for Chikungunya and Dengue were analyzed. Demographic profile, serology reports were collected over the ten year period and were analyzed year wise in two sets of five years each (2009-2013 and 2014-2018).

\section{Sample Collection}

As per the protocol of the institution, adequate blood sample was collected under aseptic conditions. Serum was separated and subjected to the laboratory investigation. Serum was stored at $-20^{\circ} \mathrm{C}$ for preservation.

\section{Sample Processing}

The sample was subjected to CHIK antibody detection. NIV Chikungunya IgM Capture ELISA kits were used. The test was performed according to the manufacturer guidelines. The results were recorded based on the OD values.

Apart from CHIK, Dengue test was also performed both for the detection of the NS1 antigen and IgM antibody based on the duration of fever. Kits used were Panbio capture ELISA for antigen detection and NIV Dengue IgM capture ELISA. The test was performed according to the manufacturer guidelines. The results were recorded based on the OD values. 


\section{RESULTS}

A total of 3676 serum samples were collected over a period of 10 years, out of which 368 were positive for CHIK IgM ELSIA.

During the first 5 years, the total samples tested were 1515 out of which, positives were 247 (16.30\%) (Chart-1). Among the positives, common age group was 31 to 40 years. Female predominance was seen among the positives. Co-infection of CHIK and dengue was seen in 14 patients.

During the next 5 years, total samples tested were 2164 and positives were 121(5.59\%). The common age group affected was 41 to 50 years. Female predominance was seen among the positives. No co-infection was noted.

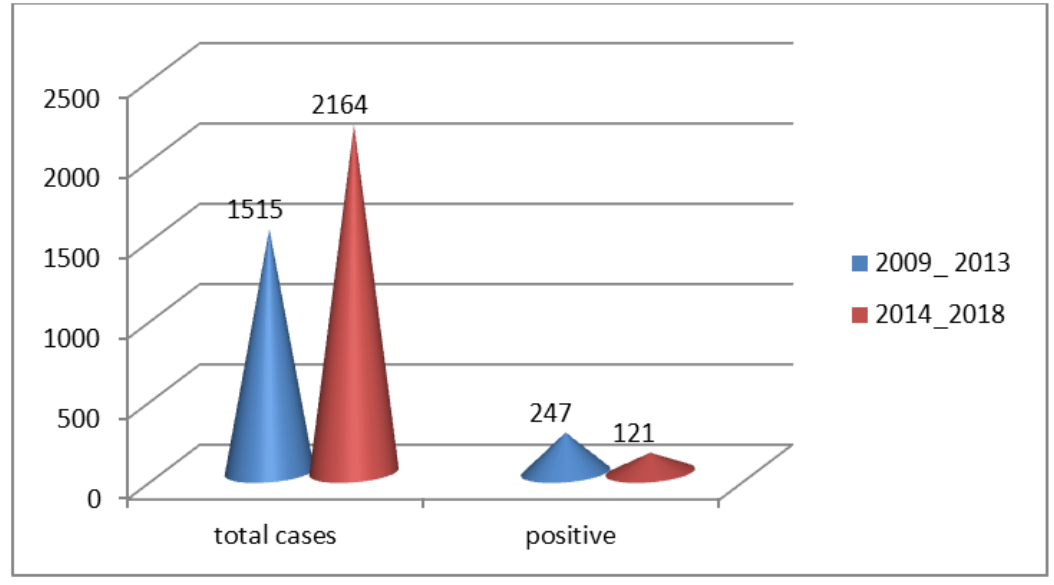

Chart-1

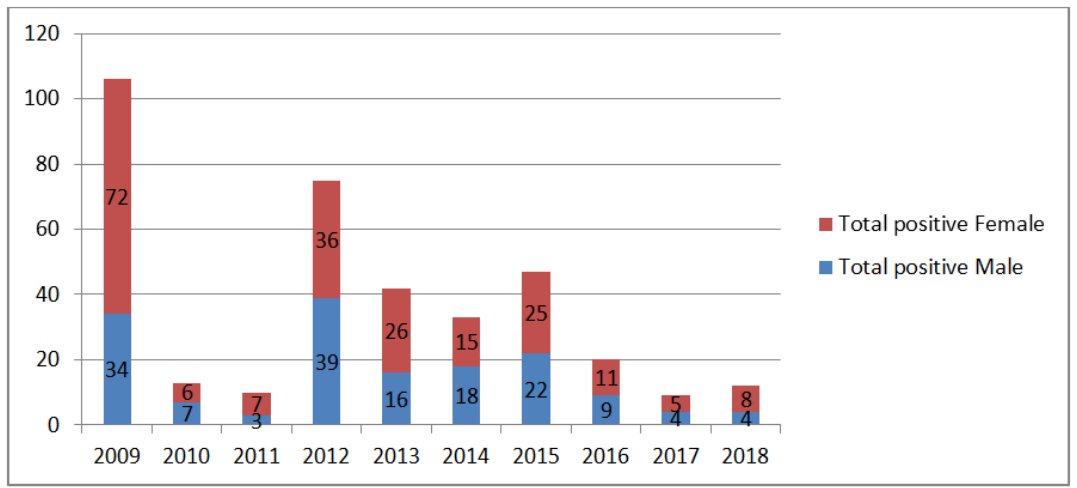

Chart-2

654 tests were done during the year 2009 which is highest for an indivisible year. Numbers of positives were also highest in the same year.

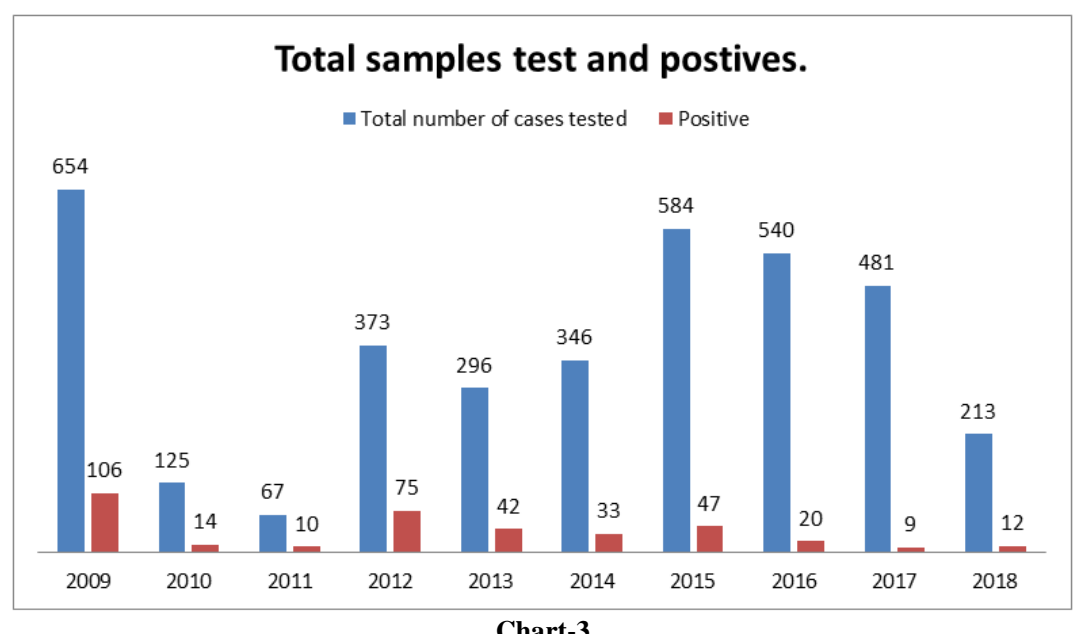

Chart-3 
In the first half of the 10 year study, highest number of the positive cases were reported in the month of November (chart 4), whereas in the second half, in the month of August (chart 5).
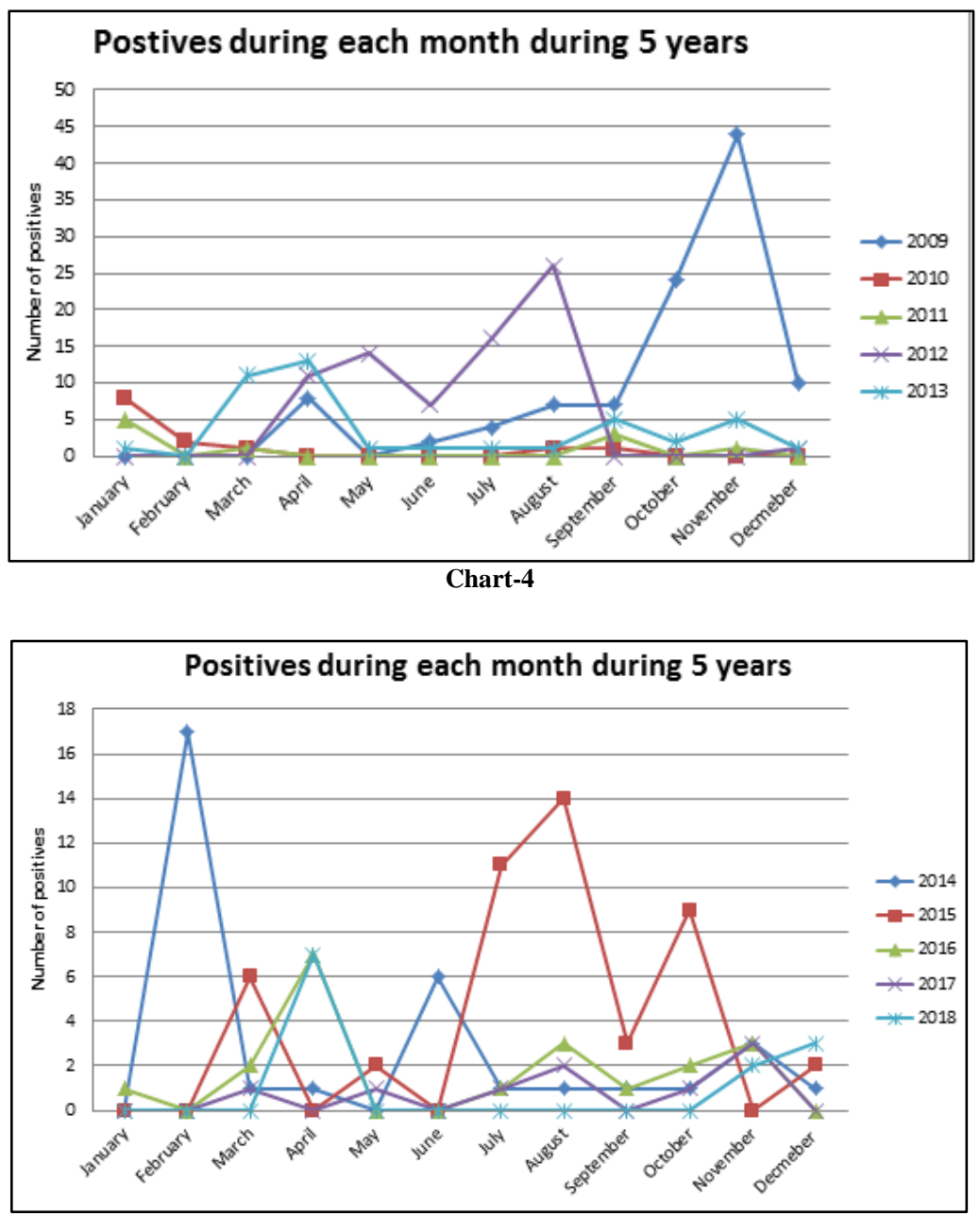

Chart-5

There were no deaths reported due to CHIKV during these periods.

\section{DISCUSSION}

There have been many outbreaks reported in India on CHIKV. First emergence was noted in 1964 by Shah et al., [12] in Calcutta region. Since then, outbreaks were reported in different parts of India. No cases were reported from 1971-2005. The re-emergence of the virus was confirmed in South India in December 2005 [13-15]. Genetic analysis of Chikungunya viruses have revealed that two distinct lineages were delineated, one containing all isolates from western Africa and the second comprising all southern and East African strains, as well as isolates from Asia [16].

The uniqueness of this study is that, a decade of data was analyzed. Many authors have reported outbreaks in a specific region during a particular season in a particular year.

In this present study, during 2009-2013 the positivity was $16.30 \%$ whereas during 2014-2018 the positivity was $5.59 \%$. This decrease in the percentage positivity is due to increase in sample size during the $2^{\text {nd }}$ five year period. $41.21 \%$ of the total samples were tested in the first half of the decade, whereas in the $2^{\text {nd }}$ half, $58.86 \%$ of the total samples were tested.

The rate of positivity in different studies cannot be compared to the present study. Chattopadhyay et al., [16] conducted a study during the year 2010 with sample size of 206 patients in West Bengal, where they have seen a positivity of $36.90 \%$, among which 31-40 years age group and females were predominant. This study was done during April to September months. In present study, in the year 2010 the positivity was $11.02 \%$ with no difference in sex predominance and more cases were seen in age group of 51-60 years. Number of positives have hit the peak during January-February.

Sudharsanam et al., [17] conducted a study in the month of August 2011 in Chennai, showed a positivity of $22.3 \%$, predominantly affecting the age group of 15-44 years and females. In the present study, 
in year 2011 the positivity was $14.92 \%$, predominantly affecting the age group 31-40 years and females.

Co-infection of CHIKV and dengue was studied by Shaikh et al., [18] in various hospitals in Karnataka and dual infection was seen from 5.7-9.5\%. Kalawat [19] conducted a study in Andhra Pradesh and saw $2.7 \%$ of dual infection. In the present study, dual infection was $5.66 \%$ during the $1^{\text {st }}$ five year period.

CHIKV is a self-limiting disease and rarely fatal. There is no vaccine developed yet. Vector control is important for prevention of the infection.

\section{CONCLUSION}

Re-emergence of CHIKV in South India was seen in 2005, CHIKV caused periodic outbreaks to be recognized as a global pathogen. Given that outbreaks caused by CHIKV have continued and becoming endemic in this area. There is increased morbidity seen but the mortality is very less. Vector control is the only prevention.

\section{ACKNOWLEDGMENTS}

I would like to thank the Veeranjaneyulu, Kishore, Roja Rani and Shiva for performing the tests.

\section{REFERENCES}

1. Apurba, S. S., \& Sandhya, B. K. Essentials of medical microbiology, 2nd edition. Jaypee brothers medical publishers 1td. 501-513

2. Mehta, K. D., Malik, S., Singh, K. P., \& Dhole, T. N. (2016). Emergence of chikungunya infection in North India. Annals of Pathology and Laboratory Medicine, 3(4), A314-319.

3. Robinson, M. C. (1955). An epidemic of virus disease in Southern Province, Tanganyika territory, in 1952-1953. Transactions of the Royal Society of Tropical Medicine and Hygiene, 49(1), 28-32.

4. Jupp, P. G., McIntosh, B. M., \& Monath, T. P. (1988). Chikungunya virus disease, The arboviruses: epidemiology and ecology vol. II, Boca Raton, FLCRC Press, 137-57.

5. Staples, J. E., Breiman, R. F., \& Powers, M. A. (2009) Chikungunya fever: An epidemiological review of a re-emerging infectious disease. Clin Infect Dis.49:942-948.

6. Rao, T. R., \& Anderson, C. R. (1964). Concluding review on the papers on the outbreak of febrile illness with hemorrhagic manifestations in Calcutta. Indian Journal Med Res. 52:727-534.

7. Powers, A. M., \& Logue, C. H. (2007). Changing patterns of chikungunya virus: Reemergence of a zoonotic arbovirus. Journal Gen Virol, 88:23632677.

8. Schuffenecker, I., Iteman, I., Michault, A., Murri, S., Frangeul, L., Vaney, M. C., ... \& Biscornet, L.
(2006). Genome microevolution of chikungunya viruses causing the Indian Ocean outbreak. PLoS medicine, 3(7), e263.

9. Njenga, M. K., Nderitu, L., Ledermann, J. P., Ndirangu, A., Logue, C. H., Kelly, C. H. L., ... \& Powers, A. M. (2008). Tracking epidemic chikungunya virus into the Indian Ocean from East Africa. The Journal of general virology, 89(Pt 11), 2754.

10. Powers, A. M., Brault, A. C., Tesh, R. B., \& Weaver, S. C. (2000). Re-emergence of Chikungunya and O'nyong-nyong viruses: evidence for distinct geographical lineages and distant evolutionary relationships. Journal of General Virology, 81(2), 471-479.

11. Pastorino, B., Muyembe-Tamfum, J. J., Bessaud, M., Tock, F., Tolou, H., Durand, J. P., \& Peyrefitte, C. N. (2004). Epidemic resurgence of Chikungunya virus in democratic Republic of the Congo: identification of a new central African strain. Journal of medical virology, 74(2), 277282.

12. Shah, K. V., Gibbs, C. J., \& Banerjee, G. (1964). Virological Investigation of the Epidemic of Haemorrhagic Fever in Calcutta: Isolation of Three Strains of Chikungunya Virus. Indian Journal of Medical Research, 52, 676-683.

13. Enserink, M. (2006). Massive outbreak draws fresh attention to little known virus. Science, 2006; 311:1085.

14. CDC. (2006). Chikungunya Fever in India. Travelers' Health Outbreak Notice April 21, 2006. http://www.cdc.gov/travel.

15. Chikungunya and Dengue in the south west Indian Ocean. Epidemic and Pandemic Alert and Response (EPR). http:// www.who.int/csr/don/2006

16. Chattopadhyay, S., Mukherjee, R., Nandi, A., \& Bhattacharya, N. (2016). Chikungunya virus infection in west Bengal, India. Indian journal of medical microbiology, 34(2), 213-215.

17. Balasubramaniam, S. M., Krishnakumar, J., Stephen, T., Gaur, R., \& Appavoo, N. C. (2011). Prevalence of chikungunya in urban field practice area of a private medical college, Chennai. Indian journal of community medicine: official publication of Indian Association of Preventive \& Social Medicine, 36(2), 124-127.

18. Shaikh, N., Raut, C. G., \& Manjunatha, M. (2015). Co-infections with chikungunya and dengue viruses: A serological study in Karnataka State, India. Indian journal of medical microbiology, 33(3), 459.

19. Kalawat, U., Sharma, K., \& Reddy, S. (2011). Prevalence of dengue and chickungunya fever and their co-infection. Indian Journal of Pathology and Microbiology, 54(4), 844-844. 